\title{
Five-point scoring system based on clinicopathological data: A convenient criterion to determine prognosis of patients with colorectal carcinoma
}

\author{
TADAHIRO NOZOE, MAYUKO KOHNO, TOMOHIRO IGUCHI, TAKASHI MAEDA and TAKAHIRO EZAKI
}

Department of Surgery, Fukuoka Higashi Medical Center, Koga 811-3195, Japan

Received August 14, 2012; Accepted November 26, 2012

DOI: $10.3892 / \mathrm{ol} .2013 .1115$

\begin{abstract}
The aim of this study was to elucidate the significance of a novel staging criterion, a five-point scoring system (FPSS), determined by five histopathological factors of colorectal carcinoma. These factors included depth of invasion, lymph node metastasis, lymphatic invasion, venous invasion and histopathological tumor type. In total, 357 patients with colorectal carcinoma who had had been treated by surgical resection were investigated. One point was assigned to each of the five aforementioned tumor-related pathological factors. The FPSS score was determined by an aggregate of the points. A significant difference was observed between the survival of patients with FPSS scores of 0 and 1, and 2 and $3(\mathrm{P}=0.0002)$; and FPSS scores of 2 and 3 , and 4 and $5(\mathrm{P}<0.0001)$. We demonstrate that the FPSS is a convenient criterion for stratifying the prognosis of patients with colorectal carcinoma.
\end{abstract}

\section{Introduction}

While there have been many criteria for determining the prognosis of patients with malignant tumors, such as the TNM staging criteria, these serve only to provide physicians with information regarding the outcome of patients during daily clinical analysis. In a previous study, we demonstrated that the Pathological Prognostic Score (PPS), determined based on histopatological data including depth of tumor, lymph node metastasis, lymphatic invasion and venous invasion, clearly classified the prognosis of patients with colorectal carcinoma (1).

Although undifferentiated carcinoma of the colon and rectum have been reputed to possess a more aggressive potential, which leads to a worse prognosis of patients (2), the criteria

Correspondence to: Dr Tadahiro Nozoe, Department of Surgery, Fukuoka Higashi Medical Center, 1-1-1 Chidori, Koga 811-3195, Japan

E-mail: paper7777@yahoo.co.jp; nozoet@fukuokae2.hosp.go.jp

Key words: colorectal carcinoma, histopathologic feature, five-point scoring system (FPSS) for determining the prognosis of patients with colorectal carcinoma reflected by this pathological type of tumor has not yet been presented. In this study, we investigated the significance of a novel staging criterion (a five-point scoring system; FPSS) for determining the prognosis of patients with colorectal carcinoma. The FPSS comprised five histopathological categories of patients with colorectal carcinoma: Depth of tumor, lymph node metastasis, lymphatic invasion, venous invasion and histopathological tumor type.

\section{Patients and methods}

Patients. In total, 357 patients with colorectal carcinoma, who had been treated by surgical resection at the Fukuoka Higashi Medical Center from January 1997 to January 2011, were evaluated. Forty-two patients had been treated with palliative resection due to the presence of distant metastasis and/or peritoneal dissemination. No patients had been treated with neoadjuvant therapy. Patients were aged between 24 and 91 years (mean, 69) and the group comprised 214 males and 143 females. The study was approved by the Ethics Committee of Fukuoka Higashi Medical Center, Koga, Japan. Written infomed consent was obtained from the patient.

Pathological research. The clinicopathological factors were determined according to the general rules for clinical and pathological studies on cancer of the colon, rectum and anus, outlined by the Japanese Research Society for Cancer of the Colon and Rectum (3). Additionally, TNM tumor stages were determined by the TNM classification of malignant tumors prescribed by the International Union Against Cancer (4).

FPSS. FPSS scores were determined by assigning one point to a more advanced result in each of the following categories: Tumor depth (T1 and 2 vs. T3 and 4); lymph node metastasis (positive vs. negative); lymphatic invasion (positive vs. negative); venous invasion (positive vs. negative) and histopathological tumor type (differentiated vs. undifferentiated tumor). Subsequently, FPSS scores were determined by an aggregate of points for each category and ranged from 0-5.

Patient follow-up. Follow-up of patients was continued until mortality and only patients whose cause of death was colorectal 
Table I. Analysis of survival rates based on five pathological factors.

\begin{tabular}{|c|c|c|c|}
\hline Characteristic & No. of patients & 5-year SR (\%) & P-value \\
\hline \multicolumn{4}{|l|}{ Depth of tumor } \\
\hline $\mathrm{T} 1$ and $\mathrm{T} 2$ & 106 & 98.7 & \multirow[t]{2}{*}{$<0.0001$} \\
\hline $\mathrm{T} 3$ and $\mathrm{T} 4$ & 251 & 74.5 & \\
\hline \multicolumn{4}{|l|}{ Nodal metastasis } \\
\hline No & 205 & 91.4 & \multirow[t]{2}{*}{$<0.0001$} \\
\hline Yes & 152 & 68.3 & \\
\hline \multicolumn{4}{|l|}{ Lymphatic invasion } \\
\hline No & 214 & 91.4 & \multirow[t]{2}{*}{$<0.0001$} \\
\hline Yes & 143 & 67.1 & \\
\hline \multicolumn{4}{|l|}{ Venous invasion } \\
\hline No & 259 & 88.5 & \multirow[t]{2}{*}{$<0.0001$} \\
\hline Yes & 98 & 63.2 & \\
\hline \multicolumn{4}{|l|}{ Histologic type } \\
\hline Differentiated & 325 & 86.3 & \multirow[t]{2}{*}{$<0.0001$} \\
\hline Undifferentiated & 32 & 37.5 & \\
\hline
\end{tabular}

SR, survival rate.

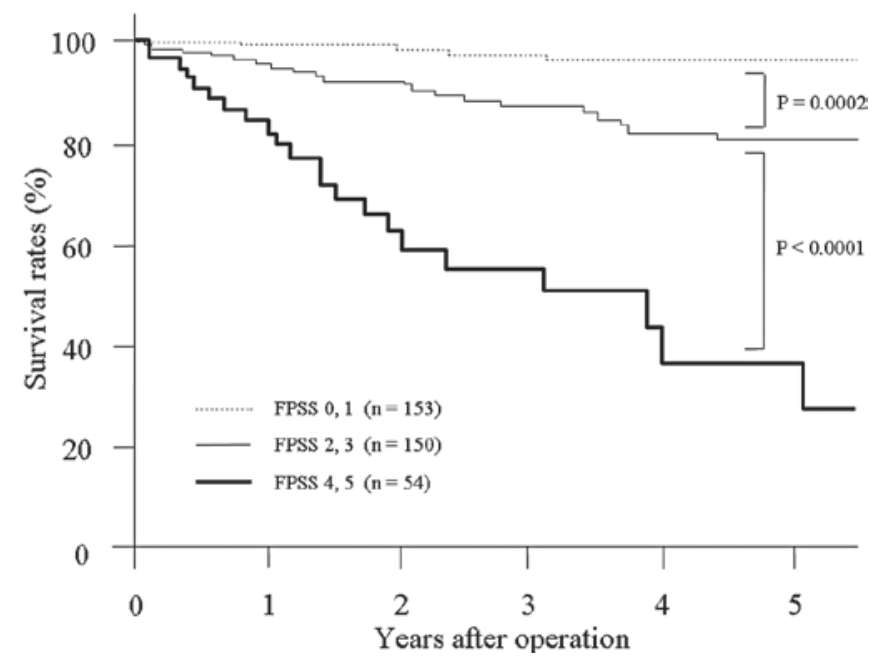

Figure 1. Survival curves. Dotted line, FPSS scores of 0 and 1; thin line, FPSS scores of 2 and 3; thick line, FPSS scores of 4 and 5. FPSS; five-point scoring system.

carcinoma were included in the tumor-related deaths. The time period between surgery and death was termed the survival time.

Statistical analysis. All statistical analyses were conducted using StatView version 5.0 (SAS Institute Inc, Cary, NC, USA). Then, a $\chi^{2}$ test was used to compare the difference in proportion values between FPSS scores. A Mann-Whitney U test was used to compare the mean ages of patients. Survival curves were conducted using the Kaplan-Meier method and a Mantel-Cox test was used to analyze their equality. $\mathrm{P}<0.05$

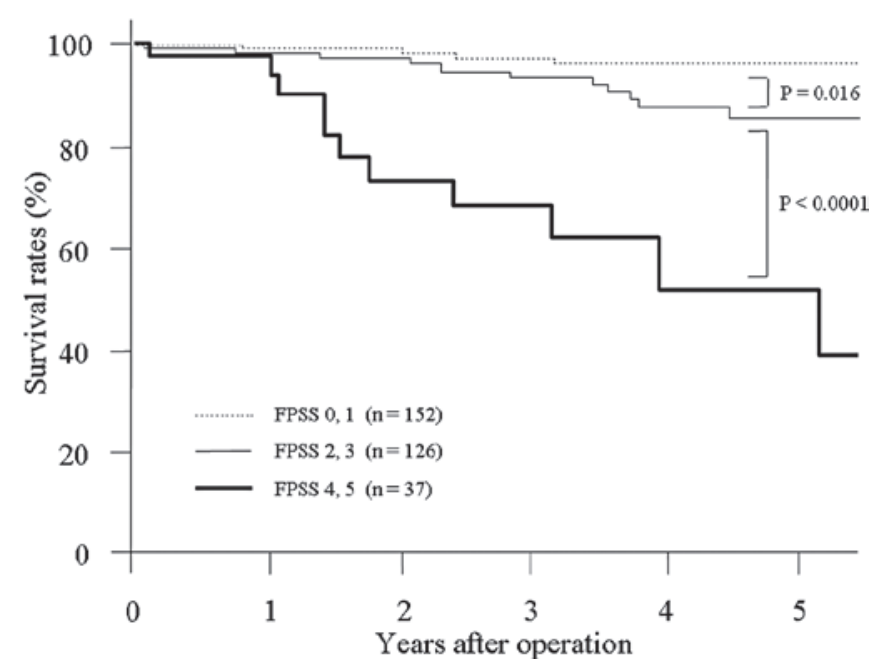

Figure 2. Survival curves for patients who had been treated with curative resection. Dotted line, FPSS scores of 0 and 1; thin line, FPSS scores of 2 and 3; thick line, FPSS scores of 4 and 5. FPSS; five-point scoring system.

was considered to indicate a statistically significant difference.

\section{Results}

Each factor included in the FPSS (tumor depth, nodal metastasis, lymphatic invasion, venous invasion and histopathological tumor type) was found to be an indicator of worse prognosis in patients with colorectal carcinoma (Table I).

The study population was divided into three groups according to the FPSS score: 0 and 1 (153 patients, 42.9\%); 2 
Table II. Correlation between FPSS score and clinicopathological characteristics of patients.

\begin{tabular}{|c|c|c|c|c|}
\hline \multirow[b]{2}{*}{ Characteristic } & \multicolumn{3}{|c|}{ No. of patients (\%) } & \multirow[b]{2}{*}{ P-value } \\
\hline & $\begin{array}{l}\text { FPSS } 0 \text { and } 1 \\
\quad(\mathrm{n}=153)\end{array}$ & $\begin{array}{l}\text { FPSS } 2 \text { and } 3 \\
\quad(\mathrm{n}=150)\end{array}$ & $\begin{array}{l}\text { FPSS } 4 \text { and } 5 \\
\quad(\mathrm{n}=54)\end{array}$ & \\
\hline \multicolumn{5}{|l|}{ Gender } \\
\hline Male & $95(62.1)$ & $92(61.3)$ & $27(50.0)$ & \multirow[t]{2}{*}{0.267} \\
\hline Female & $58(37.9)$ & $58(38.7)$ & $27(50.0)$ & \\
\hline Age (years $\pm \mathrm{SD})$ & $69.6 \pm 10.7$ & $69.8 \pm 10.9$ & $68.8 \pm 12.1$ & 0.906 \\
\hline \multicolumn{5}{|l|}{ Location of tumor } \\
\hline Colon & $108(70.6)$ & $106(70.7)$ & $38(70.4)$ & \multirow[t]{2}{*}{0.999} \\
\hline Rectum & $45(29.4)$ & $44(29.3)$ & $16(29.6)$ & \\
\hline \multicolumn{5}{|l|}{ Depth of tumor } \\
\hline $\mathrm{T} 1$ & $46(30.1)$ & 0 & 0 & \multirow[t]{4}{*}{$<0.0001$} \\
\hline $\mathrm{T} 2$ & $52(34.0)$ & $8(5.3)$ & 0 & \\
\hline $\mathrm{T} 3$ & $55(35.9)$ & $134(89.4)$ & $52(96.3)$ & \\
\hline $\mathrm{T} 4$ & 0 & $8(5.3)$ & $2(3.7)$ & \\
\hline \multicolumn{5}{|l|}{ Nodal metastasis } \\
\hline No & $147(96.1)$ & $55(36.7)$ & $3(5.6)$ & \multirow[t]{2}{*}{$<0.0001$} \\
\hline Yes & $6(3.9)$ & $95(63.3)$ & $51(94.4)$ & \\
\hline \multicolumn{5}{|c|}{ Lymphatic invasion } \\
\hline No & $146(95.4)$ & $67(44.7)$ & $1(1.9)$ & \multirow[t]{2}{*}{$<0.0001$} \\
\hline Yes & $7(4.6)$ & $83(55.3)$ & $53(98.1)$ & \\
\hline \multicolumn{5}{|l|}{ Venous invasion } \\
\hline No & $144(94.1)$ & $107(71.3)$ & $8(14.8)$ & \multirow[t]{2}{*}{$<0.0001$} \\
\hline Yes & $9(5.9)$ & $43(28.7)$ & $46(85.2)$ & \\
\hline \multicolumn{5}{|l|}{ Resection } \\
\hline Curative & $152(99.3)$ & $126(84.0)$ & $37(68.5)$ & \multirow[t]{2}{*}{$<0.0001$} \\
\hline Non-curative & $1(0.7)$ & $24(16.0)$ & $17(31.5)$ & \\
\hline
\end{tabular}

FPSS, five-point scoring system.

and 3 (150 patients, $42.0 \%$ ); and 4 and 5 (54 patients, 15.1\%). A significant correlation was observed between FPSS score and the following tumor-related factors: Tumor depth, lymph node (nodal) metastasis, lymphatic invasion, venous invasion and proportion of curative resection $(\mathrm{P}<0.0001$ for each factor; Table II).

The 1-, 3- and 5-year survival rates of patients with FPSS scores of 0 and 1 were $99.3,97.4$ and $96.2 \%$, respectively. The rates were $95.5,87.1$ and $80.5 \%$, respectively, in patients with FPSS scores of 2 and 3; and 83.8, 54.7 and 35.8\%, respectively, in patients with FPSS scores of 4 and 5. A statistically significant difference was observed between the survival of patients with FPSS scores of 0 and 1 , and 2 and $3(\mathrm{P}=0.0002)$; as well as FPSS scores of 2 and 3 , and 4 and $5(\mathrm{P}<0.0001$; Fig. 1).

Subsequently, an investigation restricted to 315 patients who had been treated with curative resection was performed. Similarly, a significant correlation was observed between FPSS scores and certain investigated tumor-related factors
(Table III). The 1-, 3- and 5-year survival rates of patients with FPSS scores of 0 and 1 were 99.3, 97.4 and 96.2\%, respectively. Such rates were 98.2, 93.6 and $85.8 \%$, respectively, in patients with FPSS scores of 2 and 3; and 97.2, 67.7 and $51.3 \%$, respectively, in patients with FPSS scores of 4 and 5. Additionally, a significant difference was observed between survival of patients with FPSS scores of 0 and 1 , and 2 and 3 $(\mathrm{P}=0.016)$; and FPSS scores of 2 and 3 , and 4 and $5(\mathrm{P}<0.0001$; Fig. 2).

\section{Discussion}

We have previously demonstrated the prognostic significance of the Pathologic Prognostic Score (PPS), determined by pathological tumor-related factors including depth of the tumor, lymph node metastasis, lymphatic invasion and venous invasion, which has provided a useful prognostic stratification for patients with gastric carcinoma (5) and colorectal carcinoma (1). 
Table III. Correlation between FPSS score and clinicopathological characteristics of patients treated with curative resection.

\begin{tabular}{|c|c|c|c|c|}
\hline \multirow[b]{2}{*}{ Characteristic } & \multicolumn{3}{|c|}{ No. of patients (\%) } & \multirow[b]{2}{*}{ P-value } \\
\hline & $\begin{array}{l}\text { FPSS } 0 \text { and } 1 \\
\qquad(\mathrm{n}=152)\end{array}$ & $\begin{array}{l}\text { FPSS } 2 \text { and } 3 \\
\quad(n=126)\end{array}$ & $\begin{array}{l}\text { FPSS } 4 \text { and } 5 \\
\quad(n=37)\end{array}$ & \\
\hline \multicolumn{5}{|l|}{ Gender } \\
\hline Male & $95(62.5)$ & $79(62.7)$ & $19(51.4)$ & \multirow[t]{2}{*}{0.419} \\
\hline Female & $57(37.5)$ & $47(37.3)$ & $18(48.6)$ & \\
\hline Age $($ years \pm SD) & $69.6 \pm 10.8$ & $70.2 \pm 11.0$ & $71.8 \pm 10.9$ & 0.268 \\
\hline \multicolumn{5}{|l|}{ Location of tumor } \\
\hline Colon & $108(71.1)$ & $92(73.0)$ & $24(64.9)$ & \multirow[t]{2}{*}{0.630} \\
\hline Rectum & $44(28.9)$ & $34(27.0)$ & $13(35.1)$ & \\
\hline \multicolumn{5}{|l|}{ Depth of tumor } \\
\hline $\mathrm{T} 1$ & $46(30.3)$ & 0 & 0 & \multirow[t]{4}{*}{$<0.0001$} \\
\hline $\mathrm{T} 2$ & $52(34.2)$ & $6(4.8)$ & 0 & \\
\hline $\mathrm{T} 3$ & $54(35.5)$ & $114(90.4)$ & $35(94.6)$ & \\
\hline $\mathrm{T} 4$ & 0 & $6(4.8)$ & $2(5.4)$ & \\
\hline \multicolumn{5}{|l|}{ Nodal metastasis } \\
\hline No & $146(96.1)$ & $48(38.1)$ & $3(8.1)$ & \multirow[t]{2}{*}{$<0.0001$} \\
\hline Yes & $6(3.9)$ & $78(61.9)$ & $34(91.9)$ & \\
\hline \multicolumn{5}{|c|}{ Lymphatic invasion } \\
\hline No & $145(95.4)$ & $56(44.4)$ & $1(2.7)$ & \multirow[t]{2}{*}{$<0.0001$} \\
\hline Yes & $7(4.6)$ & $70(55.6)$ & $36(97.3)$ & \\
\hline \multicolumn{5}{|l|}{ Venous invasion } \\
\hline No & $143(94.1)$ & $93(73.8)$ & $4(10.8)$ & \multirow[t]{2}{*}{$<0.0001$} \\
\hline Yes & $9(5.9)$ & $33(26.2)$ & $33(89.2)$ & \\
\hline
\end{tabular}

FPSS, five-point scoring system.

Poorly differentiated or undifferentiated carcinoma, including poorly differentiated adenocarcinoma and mucinous carcinoma of the colon and rectum, has been reported to possess a more aggressive biological potential compared with differentiated carcinomas (2,6-9). Certain clinical and experimental studies have been conducted to identify the subtype among colorectal poorly differentiated carcinoma that has a more progressive potential or causes a more unfavorable prognosis of patients (10-13). However, to the best of our knowledge, there have been no studies regarding a criterion for determining the tumor stage of poorly differentiated or undifferentiated colon and rectal carcinoma.

Therefore, we set out to create an evolved criterion, FPSS, based on data regarding the histopathological tumor type, separating poorly differentiated and differentiated carcinoma, in addition to PPS, to potentially determine the prognosis of patients with colorectal carcinoma. A significant difference in prognosis was found between patients who had FPSS scores of 0 and 1, and 2 and 3; and FPSS scores of 2 and 3, and 4 and 5. Therefore, there is evidence to suggest that the quality of stratification observed in the classification system was useful. Moreover, an analysis of patients who had been treated with curative resection demonstrated similar results.
As emphasized in previous studies, a novel criterion for determining the prognosis of cancer patients has the potential for simple and useful application $(1,5,14)$. While the five histopathological tumor-related factors comprising the FPSS are relatively common and the majority of medical institutes are capable of examining them, surgeons would benefit from the convenience of the clinical application of the FPSS in treating patients with colorectal carcinoma. This is due to the fact that the FPSS provides useful information regarding the clinical outcomes of patients. In conclusion, the FPSS may be a useful criteria for predicting the clinical outcome of patients with colorectal carcinoma.

\section{References}

1. Nozoe T, Mori E, Iguchi T, Kohno M, Maeda T, Ezaki T and Sueishi K: Pathological prognostic score; A rational criteria to stratify survival in colorectal carcinoma. J Surg Oncol 106: 243-247, 2012.

2. Nozoe T, Mori E, Takahashi I and Ezaki T: Preoperative elevation of serum C-reactive protein as an independent prognostic indicator of colorectal carcinoma. Surg Today 38: 597-602, 2008.

3. Japanese Society for Cancer of the Colon and Rectum: Japanese classification of colorectal carcinoma. 7th English edition. Kanehara Company, Tokyo, pp6-33, 2009. 
4. Sobin L, Gospodarowicz M and Wittekind C (eds): International Union Against Cancer. TNM classification of malignant tumours 7th edition. Wiley-Blackwell, New York, pp100-105, 2009.

5. Nozoe T, Iguchi T, Egashira A, Adachi E, Matsukuma A and Ezaki T: Pathological prognostic score as a simple criterion to predict outcome in gastric carcinoma. J Surg Oncol 102: 73-76, 2010.

6. Chung CK, Zaino RJ and Stryker JA: Colorectal carcinoma: evaluation of histologic grade and factors influencing prognosis. J Surg Oncol 21: 143-148, 1982.

7. Nozoe T, Anai H, Nasu S and Sugimachi K: Clinicopathological characteristics of mucinous carcinoma of the colon and rectum. J Surg Oncol 75: 103-107, 2000

8. Nozoe T, Inutsuka S, Honda M, Ezaki T and Korenaga D: Clinicopathologic significance of cyclin A expression in colorectal carcinoma. J Exp Clin Cancer Res 23: 127-133, 2004.

9. Takeuchi K, Kuwano H, Tsuzuki Y, Ando T, Sekihara M, Hara T and Asao T: Clinicopathological characteristics of poorly differentiated adenocarcinoma of the colon and rectum. Hepatogastroenterology 51: 1698-1702, 2004.
10. Kazama Y, Watanabe T, Kanazawa T, Tanaka J, Tanaka T and Nagawa H: Microsatellite instability in poorly differentiated adenocarcinomas of the colon and rectum: relationship to clinicopathological features. J Clin Pathol 60: 701-704, 2007.

11. Ogawa M, Watanabe M, Eto K, et al: Poorly differentiated adenocarcinoma of the colon and rectum: clinical characteristics. Hepatogastroenterology 55: 907-911, 2008.

12. Ueno $\mathrm{H}$, Mochizuki $\mathrm{H}$, Hashiguchi $\mathrm{Y}$, et al: Histological grading of colorectal cancer: a simple and objective method. Ann Surg 247:811-818, 2008

13. Ishihara S, Watanabe T, Akahane T, et al: Tumor location is a prognostic factor in poorly differentiated adenocarcinoma, mucinous adenocarcinoma, and signet-ring cell carcinoma of the colon. Int J Colorectal Dis 27: 371-379, 2012.

14. Nozoe T and Sugimachi K: Simple staging criteria for esophageal carcinoma: classification with a strict prognostic stratification. Am J Clin Oncol 26: 307-311, 2003. 